\title{
Mating activity of Bactrocera cacuminata (Hering) (Diptera: Tephritidae) on its larval host plant Solanum mauritianum Scopoli in southeast Queensland
}

\author{
R.A.I. Drew ${ }^{1 *}$, D.J. Rodgers ${ }^{1}$, S. Vijaysegaran ${ }^{1}$ \\ and C.J. Moore ${ }^{2}$ \\ ${ }^{1}$ International Centre for the Management of Pest Fruit Flies, Australian \\ School of Environmental Studies, Griffith University, Nathan Campus, \\ Queensland 4111, Australia: ${ }^{2}$ Department of Primary Industries, \\ Yeerongpilly, Queensland 4105, Australia
}

\begin{abstract}
A detailed study was conducted on the mating behaviour of Bactrocera cacuminata (Hering) (Diptera: Tephritidae) in nature. Plant tissues from Solanum mauritianum Scopoli, the primary larval host for B. cacuminata, were also analysed for methyl eugenol content. In the field, over a 15 month period, 44,171 observations of adult B. cacuminata individuals were made including 1109 mating pairs on S. mauritianum. Calling behaviour consisting of wing fanning and anus beating by males was also consistently observed on the underside of leaves of S. mauritianum after sunset. Female flies that arrived into these groups of 10-15 calling males were mated and often remained coupled until dawn. No methyl eugenol was detected from the analysis of leaves, flowers and fruits of S. mauritianum. Thus, B. cacuminata does not need to aggregate at sites where methyl eugenol is present and the hypothesis that this chemical plays a role in the selection of mating sites by B. cacuminata is not supported by the current study. It is concluded that $S$. mauritianum is the primary site of mating for B. cacuminata in nature and that the concept that the larval host plant is the centre of activity for dacine fruit flies remains robust, being fully supported by the results of this study.
\end{abstract}

Keywords: Bactrocera cacuminata, mating behaviour, host plant, methyl eugenol

(Accepted 17 April 2007)

\section{Introduction}

In a comprehensive study of the Queensland fruit fly, Bactrocera tryoni (Froggatt), in some of its major host plants (mulberry, nectarine and peach) in Brisbane, a significant tritrophic relationship between the fly, certain bacteria species and the host plant was defined (Drew \& Lloyd, 1987). In particular, the host plant was recorded as a

*Author for correspondence

Fax: +61 737353697

E-mail: d.drew@griffith.edu.au significant site for adult fly feeding, distribution of particular fruit fly-type bacteria, development of female flies to sexual maturity, courtship and mating, oviposition, larval and pupal development. Based on this study, the concept was proposed that the fruiting host plant is the 'centre of activity' for a fruit fly population. This concept has also been discussed by Drew (1987) and Drew \& Lloyd (1989, 1991). Host plant-based courtship and mating in Tephritidae has been observed for more than 50 species (Prokopy et al., 1971; Zwolfer, 1974; Aluja et al., 2000), and the strong relationship between dacine species and their host plants is believed to be significant in the processes of speciation (Drew, 2004). Additionally, the understanding of these relationships is 
important ecological knowledge that is basic to the development of improved field pest management strategies.

In contradiction to these concepts, Raghu et al. (2002) and Raghu \& Clarke (2003) reported that mating in Bactrocera cacuminata (Hering) does not occur in its primary larval host plant, Solanum mauritianum L. In a field study of the diurnal behaviour of B. cacuminata on S. mauritianum, Raghu et al. (2002) reported that they observed only feeding, resting and oviposition behaviours during the course of their experiment. Male aggregation, courtship and mating behaviour were not observed. Raghu et al. (2002) also failed to observe these behaviours on $S$. mauritianum in the field when fortnightly casual observations were carried out at post-sunset over an eight-month period across five different sites in southern Queensland. In another study, Raghu \& Clarke (2003) examined the diurnal response of B. cacuminata in a field cage containing plastic plants on which sugar, protein, methyl eugenol and leaves and fruit of S. mauritianum had been placed. Based solely on a significantly greater proportion of flies mating at the methyl eugenol site than at the other resources in their field cage experiment, they concluded that methyl eugenol acts as a mate rendezvous cue for $B$. cacuminata in its natural environment. Combined with their failure to observe mating at the larval host plant, they have proposed that B. cacuminata flies mate at a yet unknown natural methyl eugenol source away from the larval host plant.

Because of the importance of our understanding of fruit fly/host plant relationships and the marked difference in the results of Raghu et al. (2002) and Raghu \& Clarke (2003) to those in earlier literature on other tephritid species, we undertook further studies on the behavioural activities of B. cacuminata in S. mauritianum in its natural habitat. The results are reported in this paper.

\section{Materials and methods \\ Study sites}

Two field study sites were selected.

A. A large $S$. mauritianum tree $(4 \mathrm{~m}$ high with canopy diameter $4.5 \mathrm{~m}$ ) on the banks of the Logan River near Beaudesert, southeast Queensland. This is a dry, low rainfall site and was selected because of its proximity to that used by Raghu et al. (2002) at Canungra, which is approximately $18 \mathrm{~km}$ from Beaudesert. At least 100 other S. mauritianum plants were growing in the same locality. The plant community at this site was composed of ca. $100 \mathrm{~S}$. mauritianum plants interspersed with species of Eucalyptus and broadleafed trees over open grassland. The S. mauritianum consisted of plants from young non-reproductive seedlings to large mature trees flowering and fruiting.

B. Two large $S$. mauritianum trees ( $4.5 \mathrm{~m}$ high with canopy diameter $5 \mathrm{~m}$ ) growing at Cabbage Tree Creek, Everton Hills on the northwestern outskirts of Brisbane, southeast Queensland. This is approximately $65 \mathrm{~km}$ north from site A and is a moist, higher rainfall site and would be expected to have higher insect populations. Studies were conducted on one tree, the Collins Road tree (site B1), until storm destruction in late March 2004, after six months' study, necessitated moving to the second tree, the Koala Court tree (site B2), $4 \mathrm{~km}$ further upstream, within the same area and habitat type. The plant community at this site was composed of large S. mauritianum plants growing along a grassy creek
Table 1. Physical location and climatic data for study sites.

\begin{tabular}{lll}
\hline & Study site A & Study site B \\
\hline Latitude & $28.0206 \mathrm{~S}$ & $27.3617 \mathrm{~S}$ \\
Longitude & $153.0313 \mathrm{E}$ & $152.8861 \mathrm{E}$ \\
Altitude & $50 \mathrm{~m}$ & $52.7 \mathrm{~m}$ \\
Annual rainfall & $916.4 \mathrm{~mm}$ & $1108.6 \mathrm{~mm}$ \\
Temperature & & \\
- Summer min-max & $17.7-30.6^{\circ} \mathrm{C}$ & $17.6-29.3^{\circ} \mathrm{C}$ \\
- Winter min-max & $6.6-21.5^{\circ} \mathrm{C}$ & $8.2-20.9^{\circ} \mathrm{C}$ \\
\hline
\end{tabular}

bank interspersed with a variety of other species, especially broad-leafed trees.

The locations and climatic data for each study site are given in table 1. At neither site did a monoculture of S. mauritianum exist.

\section{Census of adult fly populations and mating activity}

From September 2003, for a 12-month period at study site A and a 15-month period at study sites B1and B2 combined, numbers of $B$. cacuminata adults and mating pairs were counted. Daily counts were made over the entire tree for a period of approximately one hour from sunset (the time when the sun completely disappeared over the horizon), except on rare occasions when inclement weather prevented field activities. The actual time of day of the post-sunset period varied with the annual seasonal day length cycle. Adult flies and mating pairs rest on the lower surfaces of leaves and were observed and counted by torchlight.

\section{Host plant phenology}

At site A, three large branches on the $S$. mauritianum tree were labelled and the number of flower heads and fruit heads counted fortnightly for the 15-month duration of the study. The heads were categorized into flowers, immature green fruit and mature green to yellow fruit, the latter stage being susceptible to fruit fly oviposition. The same recordings were made at sites B1 and B2 but, as they are counts from two separate trees, each for consecutive six-month periods, the data are not presented due to potential inter-tree variations, particularly those resulting from potentially different plant growing conditions. Data from site A for the period September 2003 to June 2004 were subjected to Spearman's rank correlation to determine if the total number of mating pairs observed was influenced by the abundance of mature ripe fruit.

\section{Premating and mating behaviour}

At study site B1, observations, photographic recording and filming were carried out on premating and mating behaviour of B. cacuminata on its host plant, S. mauritianum. This study was carried out on one evening, from one hour before sunset to the onset of complete darkness when premating activity had ceased and pairs of flies were in copulation. The behaviour of individuals and mating pairs was recorded. 


\section{Methyl eugenol analyses of host plant tissues}

Samples of leaves, flowers and mature fruits of S. mauritianum were taken from the tree used for the census of adult fly populations and mating activity at the Beaudesert study site A. These were collected at 8 am and transported in paper bags directly to the laboratory where chemical sampling began immediately. The time between collection and the start of sampling was less than three hours. Ambient temperature during collection, transport and analysis was in the range $20-25^{\circ} \mathrm{C}$. Headspace solidphase-microextraction (SPME, $100 \mu \mathrm{m}$ polydimethylsiloxane fibre; Supelco, Bellefonte, PA, USA) of leaves, flowers and fruit was separately performed on $c a .200 \mathrm{~g}$ samples confined in aluminium foil-covered glass jars of appropriate size, chosen so that the plant material filled the vessel. The fibre assembly was supported with a stand and clamp with the protective sheath piercing the foil. Care was taken to ensure that no contact was made between the fibre, once exposed, and the plant material, with the passive sampling then continuing for up to $3.5 \mathrm{~h}$. A sample of Huon pine (Lagarostrobos franklinii Silba) sawdust, known to contain high levels of methyl eugenol (Brophy et al., 2003) was also sampled to provide a convenient qualitative comparison. This sampling took place for $15 \mathrm{~s}$ using $10 \mathrm{~g}$ sawdust.

Gas chromatography-mass spectrometry (GCMS) was conducted on a VG TRIO-2000 instrument (VG Biotech, Altrincham, UK) using a DB-5MS column $(30 \mathrm{~m} \times 0.25 \mathrm{~mm}$ ID $\times 0.25 \mu \mathrm{m}$ film thickness; J\&W Scientific, Folsom, CA, USA). The oven was programmed from $40^{\circ} \mathrm{C}$ to $260^{\circ} \mathrm{C}$ at $10^{\circ} \mathrm{C}$ per min with an initial delay of $2 \mathrm{~min}$ and a final hold of $6 \mathrm{~min}$. The injector temperature was $250^{\circ} \mathrm{C}$, transfer line $280^{\circ} \mathrm{C}$ and ion-source $180^{\circ} \mathrm{C}$. The injector was operated in splitless mode, with the split vent programmed to open after $1 \mathrm{~min}$ and the SPME fibre left exposed in the injector for a further $10 \mathrm{~min}$ to ensure complete desorption/conditioning. The instrument included the NIST mass spectral database for automated data comparison and putative compound identification.

\section{Results \\ Census of adult fly populations and mating activity}

Over the 15-month census period, a combined total of 44,171 adult $B$. cacuminata, including 1109 mating pairs, were observed at the three study sites. This total consisted of 9522 individuals and 203 mating pairs at site A, the Beaudesert site, 25,142 individuals and 764 mating pairs at site B1, the Collins Road tree and 9507 individuals and 142 mating pairs at site B2, the Koala Court tree. At site A, a drier site with lower rainfall, the fly counts were generally lower than at sites B1 and B2, especially when the populations were at their seasonal peaks. The first mating pairs at site A were observed on 6 October 2003, 2-3 weeks after the first flies and ripe fruit were recorded. Generally, while ripe fruit were present on the tree, flies and mating pairs were also recorded, until August 2004 when all fruit had fallen and no flies were visible.

\section{Host plant phenology}

At site A, over a 15-month period, flowers were present in three cycles, each of approximately ten week duration, with ripe fruit present approximately six weeks after flowering. The largest volume of fruit was the post-winter crop from mid-September to late November 2003. No mature ripe fruit were present in December 2003. The total number of mating pairs observed was correlated with the abundance of mature ripe fruit (Spearman's correlation coefficient $=$ $0.484, p=0.111, n=12$ ).

\section{Premating and mating behaviour}

During the study, a range of premating behaviours by $B$. cacuminata on the host plant were observed and filmed. After sunset, when the light intensity fell to about 20-40 lux, male flies were observed actively flying in a loose swarm within a cluster of 10-15 S. mauritianum leaves, which occupied a volume of approximately $0.5 \mathrm{~m}^{3}$. This swarm of flies often shifted to different parts of the tree with flies darting between leaves within the cluster. The swarm then settled in one part of the tree while some males set up singleleaf territories on the underside of leaves, and others still actively flew from leaf to leaf within the cluster of leaves. Settled male flies then began rapid fanning of their wings in brief bursts accompanied by the tarsus of the hind legs being brushed against the tip of the last abdominal segment and upwards towards the vibrating wings. The leg movement alternated rapidly between the hind left and right legs. A distinct buzzing sound was also made during such wing fanning and leg movement. When another male arrived on a leaf that was already occupied by a calling male, headbutting and fights occurred with a male, usually the one that recently arrived, being evicted. Female flies that arrived into the group of calling males and individually approached a calling male were immediately mounted by the calling male. Mated pairs remained coupled on the underside of B. cacuminata leaves, often until dawn the next day.

\section{Methyl eugenol analyses of host plant tissues}

The Huon pine sawdust analysis yielded a chromatogram with one dominant peak at a retention time of $15.57 \mathrm{~min}$, constituting $>85 \%$ of the total area of all peaks. This was identified by the library-matching software as 1,2-dimethoxy-4-(2-propenyl)-benzene (methyl eugenol) with $97 \%$ confidence. Analyses of the leaves, flowers and fruit of the B.cacuminata host plant, S. mauritianum, revealed no component in the total-ion-current chromatogram at the same retention time and no component in the mass chromatogram of the abundant molecular ion at $\mathrm{m} / \mathrm{z} 178$. The estimated detection limit was $0.01 \%$ of the total integrated area of all chromatographic components in the total-ion-current chromatograms.

\section{Discussion}

The large number of mating pairs of B. cacuminata observed over a 15-month period on one host tree at Beaudesert and two host trees (each for a consecutive sixmonth period) at Everton Hills, confirmed the significance of the larval host plant, S. mauritianum, as a site of courtship and mating. At the Beaudesert site, where the host plant exhibited defined short seasonal periods of flowering and fruiting, most mating pairs were observed when ripe fruit susceptible to oviposition were present and almost no mating pairs after all fruit had fallen. This behaviour pattern is similar to that recorded for Anastrepha species where Aluja 
et al. (2000) recorded that 'mating occurs on the leaves or leaf nodes (rarely on fruits) of host trees or occasionally on the leaves of more hospitable tree canopies adjacent to hosts'.

The courtship and mating behaviour exhibited by B. cacuminata in its host plant, in this study, is similar to that recorded for other Bactrocera species. For example, the post-sunset swarming behaviour was also reported for Bactrocera tryoni (Froggatt) within a fruiting peach tree (Tyschen, 1977). Furthermore, the calling behaviour of male $B$. cacuminata, comprising rapid wing fanning, brushing of the hind legs against the anus and upwards towards the vibrating wings, by individuals positioned on the underside of the leaves of $S$. mauritianum, is similar to that described for the melon fly, Bactrocera cucurbitae (Coquillett) (Kuba \& Sokei, 1988) and Bactrocera dorsalis (Hendel) (Ohinata et al., 1982).

The SPME sampling and subsequent GCMS analyses of flowers, fruit and leaves of S. mauritianum, taken from the host plant used for the study at Beaudesert, found no evidence for the presence of the male fruit fly attractant, methyl eugenol. SPME is a simple, highly sensitive sampling technique increasingly used in the analysis of organic compounds, including fragrance compounds, at trace levels (Bartak et al., 2003; Vas \& Vekey, 2004). It complements more traditional solvent extraction/partition techniques in the analysis of volatile compounds, as well as porouspolymer-based absorption techniques. The results indicate that methyl eugenol appears not to play a role in nature as a rendezvous stimulant for mate location in these flies.

The results of this study are in contrast to those of Raghu et al. (2002) who never observed male aggregation, courtship and mating by B. cacuminata on $S$. mauritianum in a 12-day field experiment at Canungra, southeast Queensland, close to the Beaudesert site used in this study. As a result of their limited field study, Raghu et al. (2002) stated that $B$. cacuminata does not mate on its host plant and that the host is not the 'centre of activity' for fruit fly populations, a concept proposed by Drew (1987) and Drew \& Lloyd (1987).

In a subsequent experiment, Raghu \& Clarke (2003) recorded the response of adult $B$. cacuminata to four separate resources, viz., protein, sugar, methyl eugenol, leaves and fruit of $S$. mauritianum, placed on separate plastic plants in a field cage. In that study, mating pairs aggregated at the methyl eugenol site post-sunset and, as a result, the authors concluded that methyl eugenol serves as a rendezvous stimulus in mate location in nature. These results, combined with the same author's failure to observe courtship and mating on the host plant, $S$. mauritianum, led them to state that adult $B$. cacuminata does not mate on its larval host plant but elsewhere in the habitat at sites of naturally occurring methyl eugenol.

In the published work of Raghu et al. (2002) and Raghu \& Clarke (2003), they did not provide any evidence as to where, in nature, mating of B. cacuminata occurs if, in fact, it did not take place on the larval host plant. Furthermore, because they proposed a number of alternative hypotheses to refute the concept first proposed by Drew (1987) that the host plant is the 'centre of activity' for a fruit fly population, it is important to examine their experimental work in more detail. Firstly, the experiments of Raghu et al. (2002) were conducted at Canungra over a 12-day period during the month of December and involved five minute observations every hour from 6 am to $7 \mathrm{pm}$ daily. At the nearby Beaudesert site (site A) in this study, mating did not occur during December, the period after all fruit had fallen. At sites B1 and B2, the Everton Hills site, a small number of mating pairs were recorded in December but the flies did not link up until after $7 \mathrm{pm}$, the time that Raghu et al. (2002) completed their observations. As a result of their second study, Raghu \& Clarke (2003) concluded that 'methyl eugenol serves as a rendezvous stimulus in mate location' at sites other than the host plant and that 'food and mating site resources are distributed elsewhere in the habitat'. However, the courtship and mating behaviour reported in the host tree in this paper, in the absence of methyl eugenol, contradicts the Raghu \& Clarke (2003) conclusions. Until other plants are identified as sites of adult fly activities, it must be concluded that S. mauritianum is the primary, if not the only site in nature, for courtship and mating for B. cacuminata.

In conclusion, the results of this study support the conclusions of Drew (1987) and Drew \& Lloyd (1987) that the host plant is the site of courtship and mating for dacine species and that the host is the 'centre of activity' for these populations. Indeed, host plant-based behaviours appear to play a significant role in the processes of speciation (Drew, 2004) and our understanding of host plant/fruit fly ecological relationships are extremely important in the design of pest management practices.

\section{Acknowledgements}

Cameron Drew undertook a large number of the daily census activities at the Beaudesert study site, and Meredith Romig edited the final version of the manuscript. This assistance is gratefully acknowledged.

\section{References}

Aluja, M., Pinero, J., Jacome, I., Diaz-Fleischer, F. \& Sivinski, J. (2000) Behavior of flies in the Genus Anastrepha (Trypetinae: Toxotrypanini). pp. 375-406 in Aluja, M. \& Norrbom, A.L. (Eds) Fruit Flies (Tephritidae): Phylogeny and Evolution of Behavior. New York, CRC Press.

Bartak, P., Bednar, P., Lubomir, C., Ondrakova, L. \& Stransky, Z. (2003) SPME - a valuable tool for investigation of flower scent. Journal of Separation Science 26, 715-721.

Brophy, J.J., Goldsack, R.J. \& Rozefelds, A.C. (2003) Chemistry of the Australian gymnosperms - Part 5: Leaf essential oils of some endemic Tasmanian gymnosperms: Diselma archeri, Lagarostrobos franklinii, Microcachrys tetragona and Phyllocladus aspleniifolius. Journal of Essential Oil Research 15, 217-220.

Drew, R.A.I. (1987) Behavioural strategies of fruit flies of the genus Dacus (Diptera: Tephritidae) significant in mating and host-plant relationships. Bulletin of Entomological Research 77, 73-81.

Drew, R.A.I. (2004) Biogeography and speciation in the Dacini (Diptera: Tephritidae: Dacinae). pp. 165-178. in Evenhuis, N.L. \& Kaneshiro, K.Y. (Eds) D. Elmo Hardy Memorial Volume Contributions to the Systematics and Evolution of Diptera. Bishop Museum Bulletin in Entomology 12.

Drew, R.A.I. \& Lloyd, A.C. (1987) Relationship of fruit flies (Diptera: Tephritidae) and their bacteria to host plants. Annals of the Entomological Society of America 80, 629-636.

Drew, R.A.I. \& Lloyd, A.C. (1989) 3.1.3 Bacteria associated with fruit flies and their host plants. pp. 131-140 in Robinson, A.S. \& Hooper, G.H.S. (Eds) Fruit Flies, Their Biology, Natural 
Enemies and Control. Amsterdam, Elsevier Science Publishers.

Drew, R.A.I. \& Lloyd, A.C. (1991) Bacteria in the life cycle of tephritid fruit flies. pp. 441-465 in Barbosa, P., Krischik, V.A. \& Jones, C.G. (Eds) Microbial Mediation of PlantHerbivore Interactions. New York, John Wiley and Sons.

Kuba, H. \& Sokei, Y. (1988) The production of pheromone clouds by spraying in the melon fly, Dacus cucurbitae Coquillett (Diptera: Tephritidae). Journal of Ethology 6, 105-110.

Ohinata, K., Jacobson M., Kobayashi, R.M., Chambers, D.L., Fujimoto, M.S. \& Higa, H.H. (1982) Oriental fruit fly and melon fly: Biological and chemical studies of smoke produced by males. Journal of Environmental Science and Health A17, 197-216.

Prokopy, R.J., Bennett, E.W. \& Bush, G.L. (1971) Mating behaviour in Rhagoletis pomonella. Site of assembly. Canadian Entomologist 103, 1405-1409.
Raghu, S. \& Clarke, A.R. (2003) Spatial and temporal partitioning of behaviour by adult dacines: direct evidence for methyl eugenol as a mate rendezvous cue for Bactrocera cacuminata. Physiological Entomology 28, 175-184.

Raghu, S., Clarke, A.R. \& Bradley, J. (2002) Microbial mediation of fruit fly-host plant interactions: is the host plant the "centre of activity"? Oikos 97, 319-328.

Tyschen, P.H. (1977) Mating behaviour of the Queensland fruit fly, Dacus tryoni (Diptera: Tephritidae), in field cages. Journal of the Australian Entomological Society 16, 459465.

Vas, V. \& Vekey, K. (2004) Solid-phase microextraction: a powerful sample preparation tool prior to mass spectrometric analysis. Journal of Mass Spectrometry 39, 233-254.

Zwolfer, H. (1974) Das Treffpunkt - Prinzip als Kommunikationsstrategie und Isolationsmechanisms bei Bohrfliegen (Diptera: Trypetidae). Entomologia Germanica 1, 11-20. 